\title{
Clinical trial data in support of changing guidelines in osteoarthritis treatment
}

\section{Casilda M Balmaceda}

New York Neurological Consultants, New York, NY, USA
Correspondence: Casilda M Balmaceda New York Neurological Consultants, PC, 385 Fort Washington Avenue, Suite I, New York, NY 10032, USA

Tel + I 2129273327

Fax + I $212305 \mid 470$

Email casibalmacedamd@gmail.com
This article was published in the following Dove Press journal:

Journal of Pain Research

I2 April 2014

Number of times this article has been viewed
Abstract: Goals for the management of osteoarthritis (OA) emphasize pain relief, reduction of inflammation, and improvement in functioning. Among pharmacological pain management interventions, nonsteroidal anti-inflammatory drugs (NSAIDs) are frequently recommended as the most effective treatment option for OA. However, the use of traditional oral NSAIDs is associated with risk of serious adverse events involving the gastrointestinal, cardiovascular, and renal systems. Topical NSAIDs are an alternative with well-established tolerability and efficacy in the treatment of OA of the knee or hand. While the management of OA pain is evolving toward the more widespread use of topical NSAIDs, some OA management guidelines have yet to incorporate these agents in their recommendations. This review examines the efficacy and tolerability of topical NSAIDs, their current placement in OA management guidelines, and their potential role in enabling pain specialists to provide individualized care for their patients with OA.

Keywords: topical NSAIDs, diclofenac, practice guidelines, chronic pain, osteoarthritis

\section{Introduction}

Osteoarthritis (OA), the most common form of arthritis, conservatively affects 27 million adults in the USA based on 2005 population data. ${ }^{1}$ As many as one in two adults may develop symptomatic OA of the knee by age 85 ; however, among obese adults, the lifetime risk of developing OA increases to two in three. ${ }^{2} \mathrm{OA}$ of the knee is one of the top five causes of disability, with $80 \%$ of patients with the condition experiencing some degree of movement limitation affecting activities of daily living. ${ }^{3}$ Treatment options for OA include both pharmacologic and non-pharmacologic modalities. Non-pharmacologic modalities, such as exercise and weight-management programs, have been shown to be effective for overweight and obese patients experiencing OA in weight-bearing joints and should be utilized in conjunction with other therapies if possible. ${ }^{4-7}$ Pharmacologic options, including orally administered acetaminophen and nonsteroidal anti-inflammatory drugs (NSAIDs), are the most commonly utilized pharmacological options for OA. However, the risk of adverse events (AEs) with the administration of higher doses or prolonged treatment with these drugs can limit their use in some patients, particularly the elderly and those with existing hepatic, gastrointestinal, cardiovascular, and renal conditions. ${ }^{8,9}$

There are multiple approaches that can help in mitigating these risks while providing safe and effective treatment. One option is to combine analgesics with different mechanisms of action to allow for the utilization of lower doses of each 
active ingredient. ${ }^{10}$ For example, combining an NSAID (eg, etodolac or ibuprofen) with acetaminophen has been shown to effectively alleviate OA symptoms. ${ }^{11-13}$ Yet, for some of the risks associated with systemically administered agents, such as risk of cardiovascular events, it is not clear if they are dose dependent in nature. Consequently, patients may be at risk of AEs even at low doses. ${ }^{14,15}$

Another option to mitigate the risk of orally administered therapy is to provide the medication locally, thus bypassing the systemic system and limiting hepatic, gastrointestinal, cardiovascular, and renal AEs. Topical NSAIDs have only recently become available in the USA, but they have historically been more commonly utilized in other parts of the world. These agents are applied directly to the affected area, which limits their systemic exposure compared with oral NSAIDs. This review will examine the efficacy and safety of topical NSAIDs and their evolving role in OA management guidelines, as well as their potential for assisting pain specialists in providing individualized care for patients with OA.

\section{The limitations of oral NSAIDs}

NSAIDs, such as ibuprofen and naproxen, are frequently recommended as effective treatment options for OA. However, this therapy class poses a risk of serious drug interactions in patients also taking warfarin, and regular use of NSAIDs may reduce the cardioprotective effects of daily low-dose aspirin therapy. ${ }^{16-18}$ Additionally, oral NSAIDs are associated with an increased risk of potentially serious gastrointestinal, cardiovascular, and renal AEs, with the level of risk dependent on patient age and the dose and duration of NSAID use. ${ }^{19-28}$

One study found that more than $40 \%$ of oral NSAID users are at high risk for cardiovascular AEs. ${ }^{29}$ This same study also suggested that more than $85 \%$ of oral NSAID users are at significant risk for gastrointestinal AEs. ${ }^{29}$ The gastrointestinal AEs resulting from oral NSAID use are often asymptomatic and thus unrecognized by patients and providers until they become clinically significant. ${ }^{30}$ This may explain, at least in part, the bleeding, perforation, and obstruction events that occur in $1 \%-2 \%$ of patients who use oral NSAIDs. ${ }^{30}$ Because this risk of gastrointestinal AEs exists, OA treatment guidelines recommend that oral NSAIDs be used at the lowest effective dose for the shortest duration possible. ${ }^{31,32}$

\section{Limiting systemic exposure through the use of topical NSAIDs}

One option for providing effective pain relief while potentially avoiding some of the more serious systemic AEs associated with oral NSAID use is the topical application of an NSAID. ${ }^{33}$ Topically applied NSAIDs are formulated to penetrate the $\sim 10 \mu \mathrm{m}$-thick stratum corneum (the outermost layer of skin) and the underlying epidermal layer. ${ }^{34}$ Because the stratum corneum is lipophilic and the epidermal layer is aqueous, topical NSAID formulations must be both hydrophilic and lipophilic, or contain a penetration enhancer to help the applied formulation permeate the skin in effective concentrations. ${ }^{34}$ In vitro studies demonstrate that topical NSAID formulations with a higher degree of skin permeability are associated with more potent effects. ${ }^{35}$ As such, penetration enhancers, such as alcohols, propylene glycol, dimethyl sulfoxide, and water, have been used in topical NSAID formulations to increase permeability and provide more medication to the site of action. ${ }^{34,36}$

Studies in animals have found that the type of penetration enhancer used in a topical NSAID formulation influences permeability. For example, the permeability rate of diclofenac sodium across rat skin in vitro is significantly greater with a microemulsion containing dimethyl sulfoxide than with the microemulsion alone, and is significantly lower with a gel. ${ }^{37}$ Consistent with the in vitro permeability results, the in vivo anti-inflammatory effect of topically applied diclofenac sodium in rats is more pronounced using a microemulsion-based formulation (with or without dimethyl sulfoxide) than with a gel. ${ }^{37}$

All topical NSAID formulations - regardless of dosage form, molecular salt used in the formulation, use of carriermediated transport, or penetration-enhancement method used - penetrate the synovial fluid in addition to the superficial joints, ${ }^{38,39}$ which likely contributes to the efficacy of these agents. In addition, topical NSAIDs may offer improved safety compared with oral formulations because target-site application is associated with lower systemic drug concentrations, typically $<10 \%$ of those obtained after oral NSAID administration. ${ }^{38,40-42}$

NSAIDs are categorized as being either nonselective cyclooxygenase (COX) inhibitors or selective inhibitors of COX-2. ${ }^{38}$ Like oral NSAIDs, the inhibition of COX by topical NSAIDs reduces the synthesis of prostaglandin, which is involved in pain, vasodilation, and decreased sensitivity of blood vessels to bradykinin and histamine. ${ }^{43}$ In fact, the topical administration of NSAIDs results in concentrations in the tissue and synovial fluid that are sufficient to inhibit $50 \%$ of enzyme activity for prostaglandin synthesis, although there can be considerable variability in this rate. ${ }^{38}$

Additional benefits of topical NSAID application over oral administration include the elimination of first-pass metabolism, the potential for better patient adherence to 
treatment due to fewer AEs, and a decreased potential for drug-drug interactions - a benefit that may be especially important in elderly patients with OA who often have multiple comorbidities and receive treatment with multiple drugs. ${ }^{36,38,44}$ Data collected in the European Union suggest that the reduced cardiovascular and gastrointestinal AEs observed with the use of topical NSAIDs may also result in long-term cost savings over oral NSAIDs by reducing the need to use concomitant cardiovascular- and gastrointestinalprotective agents. ${ }^{45}$

\section{Efficacy of topical NSAIDs in relieving OA pain}

NSAIDs that are available in topical formulations include ketoprofen, diclofenac, ibuprofen, eltenac, felbinac, and piroxicam, all of which have been available in the European Union for more than a decade. ${ }^{36,46}$ Among the topical NSAIDs, topical diclofenac, available as a spray, gel, patch, bio-adhesive plaster, or lotion, has been most extensively tested against placebo in the treatment of OArelated pain. ${ }^{39,41,47}$

Only two topical diclofenac formulations have been approved in the USA for the treatment of OA: diclofenac sodium 1\% topical gel (Endo Pharmaceuticals Inc., Chadds Ford, PA, USA; 2007) ${ }^{48}$ and diclofenac sodium $1.5 \%$ topical solution (Mallinckrodt Inc, Hazelwood, MO, USA; 2009). ${ }^{49}$ A third topical diclofenac formulation, diclofenac epolamine $1.3 \%$ topical patch (King Pharmaceuticals Inc, Bristol, TN, USA; 2008), has been approved in the USA for the treatment of pain due to minor strains, sprains, and contusions,,$^{50}$ but it has not received approval for the treatment of OA. These three topical diclofenac formulations differ in the penetration enhancer utilized, dosage form, and degree of systemic absorption (Table 1). ${ }^{36,48-51}$

Several systematic reviews have compared the shortterm (2-4 weeks) effects of topical NSAIDs with those of placebo and consistently demonstrated statistically significant improvements in pain at 2 weeks, beyond what could be attributed to rubbing alone. ${ }^{46,52}$ Mason et al conducted a meta-analysis of data from 14 randomized, double-blind, placebo-controlled trials involving nearly 600 patients with OA of the knee; compared with placebo, the relative benefit of topical NSAIDs was 2.0 (95\% confidence interval [CI], 1.6-2.6). ${ }^{46}$ Lin et al conducted an independent metaanalysis and reported that topical NSAIDs were superior to placebo in relieving pain due to OA in the first 2 weeks of treatment, but not in weeks 3 and $4 .^{52}$ For weeks 1 and 2, the effect sizes observed in this study were 0.41 (95\% CI, $0.16-0.66)$ and $0.40(0.15-0.65)$, respectively. Likewise, topical NSAIDs produced a greater improvement in functioning in weeks 1 and 2 but not in weeks 3 and 4, when compared with placebo. ${ }^{52}$

More recently, Barthel et al conducted a 12-week, randomized, double-blind, vehicle-controlled, parallel-group, multicenter trial of diclofenac sodium 1\% topical gel in 492 patients with OA of the knee and found that diclofenac sodium topical gel was superior to a vehicle control, in reducing pain scores $(-5.0$ versus (vs) -4.0 , respectively; $P=0.01$ ) and improving functioning $(-15.0$ vs -10.9 , respectively; $P=0.001)$ and patient global disease ratings $(-27.0 \mathrm{vs}-18.2$, respectively; $P<0.001)$ throughout the study period. ${ }^{53}$ In a 12-week, randomized, vehicle-controlled, multicenter trial conducted with diclofenac sodium 1.5\% topical solution in 326 patients with OA of the knee, Roth and Shainhouse found greater improvements in pain $(-5.9 \mathrm{vs}-4.3 ; P<0.005)$, physical function $(-15.4$ vs $-10.1 ; P<0.005)$, patient global assessment $(-1.3$ vs $-0.9 ; P<0.005)$, and stiffness $(-1.8$ vs $-1.3 ; P<0.01)$ among patients who received diclofenac sodium $1.5 \%$ topical solution than among those who received a vehicle control, respectively. ${ }^{54}$ In a 2 -week, randomized, double-blind, placebo-controlled trial conducted by Brühlmann and Michel with diclofenac epolamine $1.3 \%$ topical patch in 103 patients with OA of the knee, a significant difference in favor of the topical diclofenac patch in the two

Table I Topical nonsteroidal anti-inflammatory drug formulations currently approved for use by prescription in the USA

\begin{tabular}{|c|c|c|c|c|}
\hline Molecular salt & Formulation & $\begin{array}{l}\text { Main penetration } \\
\text { enhancer(s) }\end{array}$ & Dosage & Peak plasma concentration \\
\hline Diclofenac sodium & I\% gel & $\begin{array}{l}\text { Isopropyl alcohol, } \\
\text { propylene glycol, water }\end{array}$ & $\begin{array}{l}2 \mathrm{~g} \text { (elbow, wrist, hand) or } 4 \mathrm{~g} \\
\text { (knee, ankle, foot), } 4 \times \text { daily }\end{array}$ & $\begin{array}{l}\text { I5.0 } \pm 7.3 \mathrm{ng} / \mathrm{mL}(4 \mathrm{~g}, 4 \times \text { daily, } 7 \mathrm{~d}) \\
53.8 \pm 32.0 \mathrm{ng} / \mathrm{mL}(12 \mathrm{~g}, 4 \times \text { daily, } 7 \mathrm{~d})\end{array}$ \\
\hline Diclofenac sodium & $\begin{array}{l}\mathrm{I} .5 \% \mathrm{w} / \mathrm{w} \\
\text { topical solution }\end{array}$ & $\begin{array}{l}45.5 \% \mathrm{w} / \mathrm{w} \text { dimethyl } \\
\text { sulfoxide }\end{array}$ & 40 drops, $4 \times$ daily & $\begin{array}{l}\text { 8. I } \pm 5.9 \mathrm{ng} / \mathrm{mL}(80 \text { drops, I } \times) \\
19.4 \pm 9.3 \mathrm{ng} / \mathrm{mL}(80 \text { drops, } 4 \times \text { daily, } 7 \mathrm{~d})\end{array}$ \\
\hline Diclofenac epolamine & Patch & None ${ }^{a}$ & One $180 \mathrm{mg}$ patch, $2 \times$ daily & I.3-8.8 ng/mL (I patch, $2 \times$ daily, $5 \mathrm{~d}$ ) \\
\hline
\end{tabular}

Notes: ${ }^{2}$ Diclofenac epolamine, in contrast to diclofenac sodium, is sufficiently lipophilic to not require a penetration enhancer. ${ }^{1 !}$

This table is based on data provided in Barkin, ${ }^{36}$ with additional data from Herndon ${ }^{51}$ and the prescribing information for each product. ${ }^{48-50}$

Abbreviations: $d$, days; w/w, weight per weight. 
primary outcome measures (ie, the Lequesne Algofunctional Index and spontaneous pain scores) was observed beginning on day 4 and extended to day $14 .{ }^{55}$

Only two clinical trials have directly compared the efficacy of topical diclofenac with that of oral diclofenac. A 12-week, randomized, double-blind, double-dummy, controlled, multicenter trial conducted in 775 patients with OA of the knee by Simon et al comparing diclofenac sodium $1.5 \%$ topical solution with placebo, a dimethyl sulfoxide vehicle, oral diclofenac, and the combination of the topical diclofenac solution and oral diclofenac demonstrated that diclofenac sodium $1.5 \%$ topical solution was superior to both placebo and the dimethyl sulfoxide vehicle in reducing pain $(P<0.05)$ and improving function $(P<0.05)$. In addition, diclofenac sodium $1.5 \%$ topical solution was superior to placebo and the vehicle control in scores on patient overall health assessment $(P<0.05)$ at the end of the study period. ${ }^{56}$ No significant difference was found between diclofenac sodium $1.5 \%$ topical solution and oral diclofenac in pain ( -6.0 vs -6.4 , respectively; $P=0.429$ ) or physical functioning ( -15.8 vs -17.5 , respectively; $P=0.319$ ), and the combination of topical and oral diclofenac did not produce greater effects than oral diclofenac alone. ${ }^{56}$

Tugwell et al also demonstrated in a randomized, doubleblind, multicenter trial of 622 patients with OA of the knee that the efficacy of diclofenac sodium $1.5 \%$ topical solution provided equivalent degrees of improvement in pain relief compared with oral diclofenac ( $44 \%$ vs $49 \%$, respectively; $P=0.23) .{ }^{57}$ This evidence is further supported by a recent Cochrane Database review, which demonstrated that topical NSAID formulations, particularly those that utilize diclofenac, produce consistent efficacy comparable with oral NSAIDs for the treatment of chronic musculoskeletal pain. ${ }^{58}$

\section{Safety profile of topical NSAIDs}

The safety of topical NSAIDs has been evaluated in clinical trials, pooled analyses, and systematic reviews. A systematic review conducted by Makris et al identified 16 randomized, controlled trials that evaluated the AEs associated with topical or oral NSAIDs in older adults (mean age, 60-67 years) with $\mathrm{OA} ;{ }^{59}$ in both topical and oral NSAID groups, gastrointestinal complaints and headache were the most frequently reported systemic AEs. Anemia, liver function changes, renal abnormalities, and "severe" gastrointestinal AEs were more frequent among oral NSAID users (Table 2). ${ }^{58,59}$ In addition, based on an independent review of 19 randomized, doubleblind, controlled trials that evaluated the use of topical diclofenac formulations for treating OA and soft-tissue
Table 2 Systemic adverse events among randomized controlled trials

\begin{tabular}{|c|c|c|c|c|}
\hline \multirow[t]{2}{*}{$\begin{array}{l}\text { Adverse } \\
\text { effect }\end{array}$} & \multicolumn{4}{|c|}{$\begin{array}{l}\text { Treatment group/drug administration }{ }^{a} \\
\text { (range, \%) }\end{array}$} \\
\hline & Topical & Oral & Vehicle $^{b}$ & Placebo \\
\hline Upper GI NOS & 10.3 & 8.5 & - & - \\
\hline GINOS & $2.6-4.8$ & $0.8-13.4$ & - & 7.3 \\
\hline Abdominal pain & $1.4-12.0$ & $3.0-22.0$ & $0.9-3.1$ & $0.6-2.4$ \\
\hline Dyspepsia & $0.7-15.0$ & $3.0-26.0$ & $0.9-5.0$ & $0.8-6.0$ \\
\hline Gastritis & $0.9-2.2$ & 0.0 & 0.0 & $0.0-2.4$ \\
\hline Nausea & $0.0-8.0$ & $2.0-13.0$ & $0.6-5.6$ & 0.0 \\
\hline Diarrhea & $0.0-9.0$ & $1.5-17.0$ & $0.0-2.0$ & $0.0-4.0$ \\
\hline Constipation & $0.9-8.0$ & $0.0-10.0$ & $0.6-1.0$ & 1.0 \\
\hline Gl bleed ${ }^{c}$ & $0.0-1.0$ & $0.0-2.0$ & $0.0-1.2$ & 0.0 \\
\hline Halitosis & $0.0-5.0$ & 0.3 & $0.0-1.2$ & 0.0 \\
\hline $\begin{array}{c}\text { Liver function } \\
\text { abnormality }\end{array}$ & $0.0-6.9$ & $7.9-19.6$ & $1.3-5.3$ & $0.6-4.2$ \\
\hline $\begin{array}{l}\text { Renal } \\
\text { abnormality }^{d}\end{array}$ & $0.0-7.6$ & $7.2-10.0$ & 6.0 & $0.0-5.7$ \\
\hline $\begin{array}{l}\text { Change } \\
\text { in hemoglobin }\end{array}$ & $0.0-2.1$ & $5.8-10.0$ & 3.3 & 4.9 \\
\hline $\begin{array}{l}\text { Respiratory } \\
\text { disordere }\end{array}$ & $0.0-3.2$ & $2.0-5.3$ & $0.5-2.5$ & 3.8 \\
\hline CNS NOS & $6.0-9.5$ & $6.8-7.3$ & - & 4.9 \\
\hline Dizziness & $0.6-1.2$ & 4.0 & 0.0 & - \\
\hline Vertigo & $0.0-1.0$ & - & - & - \\
\hline Headache & $5.0-17.5$ & $6.0-17.2$ & $4.3-13.0$ & 11.5 \\
\hline
\end{tabular}

Notes: ${ }^{T}$ The studies from which these numbers were retrieved were heterogeneous and were included as part of a review of the literature rather than a meta-analysis, ${ }^{59}$ bvehicle contains dimethyl sulfoxide and pluronic lecithin organogel base, or isopropyl alcohol, propylene glycol, cocoyl caprylocaprate, mineral oil, ammonia solution, perfume

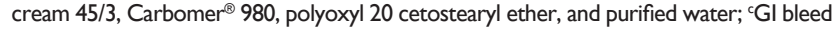
includes melena and rectal hemorrhage; 'percentage of patients changing from normal to

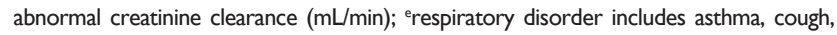
and dyspnea.

Copyright (c) 2010. The Journal of Rheumatology. Reproduced with permission of Makris UE, Kohler MJ, Fraenkel L. Adverse effects of topical nonsteroidal antiinflammatory drugs in older adults with osteoarthritis: a systematic literature review.J Rheumatol. 2010;37(6):1236-1243.59

Abbreviations: CNS, central nervous system; Gl, gastrointestinal; NOS, not otherwise specified.

injuries/disorders, Zacher et al concluded that the safety and tolerability profiles of topical diclofenac were deemed fair to excellent in the vast majority of patients. ${ }^{60}$ The primary tolerability issues seen with these formulations involved dermatological reactions (eg, rash).

In a double-blind, randomized, multicenter clinical trial, Zacher et al found that diclofenac sodium 1\% topical gel was at least as effective in reducing pain as oral ibuprofen in OA of the hand, with the gel demonstrating a reduced rate of gastrointestinal AEs. ${ }^{61}$ A pooled analysis of data conducted by Baraf et al from five randomized, double-blind, placebo-controlled trials of OA of the knee or hand found that in comparison with placebo, treatment with diclofenac sodium $1 \%$ topical gel resulted in a similar frequency of AEs in patients $\geq 65$ years of age compared with younger patients. ${ }^{62} \mathrm{~A}$ post hoc analysis ${ }^{63}$ that was 
conducted to assess the longer-term safety of diclofenac sodium $1 \%$ gel suggests that patients $\geq 65$ years of age do not have a greater risk of experiencing AEs than those who are $<65$ years of age. Additionally, the overall rate of AEs and the subset of AEs involving the gastrointestinal system were not affected by the presence of medical comorbidities; however, patients with cardiovascular or cerebrovascular comorbidities were more likely to experience cardiovascular-related AEs. ${ }^{63}$

Tugwell et al found a decrease in the incidence of gastrointestinal AEs and abnormal liver test function after diclofenac sodium $1.5 \%$ topical solution administration for treatment of OA of the knee when compared with oral diclofenac. ${ }^{57}$ Simon et al found that the incidence of gastrointestinal AEs after treatment with diclofenac sodium 1.5\% topical solution for OA of the knee was no greater than the rate observed after treatment with placebo and was lower than the rate seen following treatment with oral diclofenac. ${ }^{56}$ This same study showed that the incidence of cardiovascular AEs was rare and did not differ among the treatment groups, but abnormal liver function tests were more common after treatment with oral diclofenac. ${ }^{56}$

A pooled safety analysis of data from two trials on OA of the knee conducted by Roth and Fuller similarly found that gastrointestinal AEs and abnormal liver and renal function tests were more common after treatment with oral diclofenac than with diclofenac sodium $1.5 \%$ topical solution, but the incidence of cardiovascular AEs was low and did not differ significantly between the groups. ${ }^{64}$

In the majority of these studies, application-site-related AEs were more common following use of topical diclofenac than after administration of placebo or oral NSAIDs, although the AEs resulting from topical diclofenac use were generally tolerable (Table 2). ${ }^{56,57,59,62,64}$

\section{The status of OA treatment guidelines}

Given the proven efficacy and tolerability of topical NSAIDs, they are now included in a number of international guidelines for the treatment of patients with OA of the hand or knee (Table 3). ${ }^{65-67}$ Some treatment guidelines have further recommended that topical NSAIDs be considered for use before oral analgesics. For example, guidelines from the National Institute for Health and Clinical Excellence recommend that topical NSAIDs be used before oral NSAIDs, COX-2 selective inhibitors, or opioids. ${ }^{68,69}$ The European League Against Rheumatism considers topical NSAIDs safe and efficacious in the treatment of OA of the knee, but it does not give specific recommendations. ${ }^{70}$ For the treatment of OA of the hand, the European League Against Rheumatism recommends topical treatments over systemic treatments. ${ }^{31}$ The Osteoarthritis Research Society International recommends the use of topical NSAIDs in patients who are unresponsive to first-line treatment with acetaminophen. ${ }^{32}$

Before 2007, when topical NSAID formulations received approval by the US Food and Drug Administration, topical NSAIDs were not included in US treatment guidelines for OA, in contrast with European Union guidelines. However, after US Food and Drug Administration approval of topical NSAIDs, the American Academy of Orthopaedic Surgeons updated its recommendations to strongly recommend oral or topical NSAIDs as first-line therapy for all patients with OA of the knee. ${ }^{67,71}$ The most recent guidelines from the American

Table 3 Recommendations for topical analgesics in OA treatment guidelines

\begin{tabular}{|c|c|}
\hline Guideline & Recommendation(s) \\
\hline AAOS & Knee OA: strong recommendation to use oral or topical NSAIDs or tramadol \\
\hline \multirow[t]{3}{*}{ ACR } & $\begin{array}{l}\text { Hand OA: topical capsaicin, topical NSAIDs (including trolamine salicylate), oral NSAIDs (including COX-2 inhibitors), or tramadol } \\
\text { should be considered }\end{array}$ \\
\hline & Knee OA: acetaminophen, oral or topical NSAIDs, tramadol, or intra-articular corticosteroid injections should be considered \\
\hline & Hand or knee OA: for patients aged 75 years or older, topical NSAIDs, rather than oral NSAIDs, are recommended \\
\hline AGS & Localized, non-neuropathic, persistent pain: all patients may be candidates for topical NSAIDs \\
\hline \multirow[t]{2}{*}{ EULAR } & $\begin{array}{l}\text { Hand OA: topical treatments are preferred over systemic treatments, especially for mild to moderate pain and when only a few } \\
\text { joints are affected }\end{array}$ \\
\hline & Knee OA: topical NSAIDs and capsaicin have clinical efficacy and are safe \\
\hline NICE & $\begin{array}{l}\text { Knee or hand OA: topical NSAIDs should be considered for pain relief in addition to core treatment. Topical NSAIDs and/or } \\
\text { acetaminophen should be considered ahead of oral NSAIDs, COX-2 inhibitors, or opioids }\end{array}$ \\
\hline OARSI & $\begin{array}{l}\text { Knee OA: topical NSAIDs and capsaicin may be considered as adjunctives or alternatives to oral analgesics or anti-inflammatory } \\
\text { agents }\end{array}$ \\
\hline Note: Copyright @ 201 I. Springer Healthcare. Adapted with permission of Altman RD, Barthel HR. Topical therapies for osteo & Additional data from Hochberg et al and AAOS..$^{66-67}$ \\
\hline \multicolumn{2}{|c|}{$\begin{array}{l}\text { Abbreviations: AAOS, American Association of Orthopaedic Surgeons; ACR, American College of Rheumatology; AGS, American Geriatric Society; COX, cyclooxygenase; } \\
\text { EULAR, European League Against Rheumatism; NICE, National Institute for Health and Clinical Excellence; NSAID, nonsteroidal anti-inflammatory drug; OA, osteoarthritis; } \\
\text { OARSI, Osteoarthritis Research Society International. }\end{array}$} \\
\hline
\end{tabular}


Geriatric Society also recommend the use of topical analgesics in all patients with localized non-neuropathic pain. ${ }^{72}$ The American Pain Society's most recent guidelines on OA are from $2002 ;^{73}$ therefore, recommendations regarding the use of topical NSAIDs are currently unavailable from the American Pain Society.

In 2012, the American College of Rheumatology updated its recommendations to conditionally recommend that patients with OA of the hand be treated with either topical or oral NSAIDs, topical capsaicin, or tramadol. ${ }^{66}$ For the treatment of OA of the knee, the new American College of Rheumatology guidelines conditionally recommend the use of acetaminophen, oral or topical NSAIDs, tramadol, or intra-articular corticosteroid injections. Further, the American College of Rheumatology guidelines recommend that elderly individuals over the age of 75 years who are in need of an NSAID should be treated with topical, rather than oral, NSAIDs. ${ }^{66}$

Countries in the European Union have been using topical NSAIDs for more than a decade, while the USA has only recently approved their use for the treatment of OA. As both the amount of data related to the increased risks associated with oral NSAIDs and the clinical experience with topical NSAIDs continue to increase, clinical management guidelines can quickly become out of date if not updated frequently. Attempting to understand the human condition of pain requires a pluralistic approach that incorporates data to create a true "world literature" that supports global remedies for pain. ${ }^{74}$ As medicine becomes increasingly globalized, international clinical guidelines for the management of OA that deliver consistent diagnostic and treatment approaches are becoming increasingly important to pain specialists in the European Union, the USA, and around the world.

\section{Conclusion}

Although highly effective for relieving pain, oral nonselective NSAIDs are associated with serious AEs; ${ }^{20-26}$ however, this risk may be reduced with the use of topical NSAID formulations. It is important that pain specialists are aware of changes in recommendations for use of oral and topical NSAIDs, based on recent OA guidelines. Topical NSAIDs provide a well-tolerated alternative approach to achieving pain relief with minimal risk of serious AEs. In patients with OA, topical NSAIDs have been shown to have superior efficacy compared with placebo and equivalent efficacy compared with oral NSAIDs, with no increase in the risk of serious AEs. ${ }^{46,52,58}$ These data suggest that the reduced incidence of cardiovascular and gastrointestinal AEs observed with the use of topical NSAIDs may make them useful in patients who are at high risk.

Optimal management of the pain associated with OA requires awareness and selection of the pharmacologic treatments and non-pharmacologic interventions that best meet a given patient's needs. For patients with OA of the knee or hand, the elderly, or those with certain comorbidities, topical NSAIDs may be the most effective tool for pain management, particularly because of the lower risk of gastrointestinal and cardiovascular AEs. The recommendations included in the newly updated American College of Rheumatology treatment guidelines regarding the use of topical NSAIDs in the treatment of OA of the knee or hand and in the elderly will be helpful in guiding pain specialists around the world on best practices in OA treatment in this population.

\section{Acknowledgments}

Technical editorial and writing support for the preparation of this manuscript was provided by Lauren Burawski, MA, Synchrony Medical Communications, LLC, West Chester, PA, USA. Funding for this support was provided by Mallinckrodt Inc, Hazelwood, MO, USA.

\section{Disclosure}

The author declares no conflicts of interest in this work.

\section{References}

1. Lawrence RC, Felson DT, Helmick CG, et al; National Arthritis Data Workgroup. Estimates of the prevalence of arthritis and other rheumatic conditions in the United States. Part II. Arthritis Rheum. 2008;58(1): 26-35.

2. Murphy L, Schwartz TA, Helmick CG, et al. Lifetime risk of symptomatic knee osteoarthritis. Arthritis Rheum. 2008;59(9):1207-1213.

3. Guccione AA, Felson DT, Anderson JJ, et al. The effects of specific medical conditions on the functional limitations of elders in the Framingham Study. Am J Pub Health. 1994;84(3):351-358.

4. Christensen R, Bartels EM, Astrup A, Bliddal H. Effect of weight reduction in obese patients diagnosed with knee osteoarthritis: a systematic review and meta-analysis. Ann Rheum Dis. 2007;66(4):433-439.

5. Batterham SI, Heywood S, Keating JL. Systematic review and metaanalysis comparing land and aquatic exercise for people with hip or knee arthritis on function, mobility and other health outcomes. $B M C$ Musculoskelet Disord. 2011;12:123.

6. Deyle GD, Henderson NE, Matekel RL, Ryder MG, Garber MB, Allison SC. Effectiveness of manual physical therapy and exercise in osteoarthritis of the knee. A randomized, controlled trial. Ann Intern Med. 2000;132(3):173-181.

7. Pisters MF, Veenhof C, Schellevis FG, De Bakker DG, Dekker J. Long-term effectiveness of exercise therapy in patients with osteoarthritis of the hip or knee: a randomized controlled trial comparing two different physical therapy interventions. Osteoarthritis Cartilage. 2010;18(8): 1019-1026.

8. Barkin RL, Beckerman M, Blum SL, Clark FM, Koh EK, Wu DS. Should nonsteroidal anti-inflammatory drugs (NSAIDs) be prescribed to the older adult? Drugs Aging. 2010;27(10):775-789. 
9. Watkins PB, Kaplowitz N, Slattery JT, et al. Aminotransferase elevations in healthy adults receiving 4 grams of acetaminophen daily: a randomized controlled trial. JAMA. 2006;296(1):87-93.

10. Raffa RB. Pharmacology of oral combination analgesics: rational therapy for pain. J Clin Pharm Ther. 2001;26(4):257-264.

11. Doherty M, Hawkey C, Goulder M, et al. A randomised controlled trial of ibuprofen, paracetamol or a combination tablet of ibuprofen/ paracetamol in community-derived people with knee pain. Ann Rheum Dis. 2011;70(9):1534-1541

12. Pareek A, Chandurkar N, Ambade R, Chandanvale A, Bartakke G. Efficacy and safety of etodolac-paracetamol fixed dose combination in patients with knee osteoarthritis flare-up: a randomized, double-blind comparative evaluation. Clin J Pain. 2010;26(7):561-566.

13. Pareek A, Chandurkar N, Sharma VD, Desai M, Kini S, Bartakke G A randomized, multicentric, comparative evaluation of aceclofenacparacetamol combination with aceclofenac alone in Indian patients with osteoarthritis flare-up. Expert Opin Pharmacother. 2009;10(5): 727-735.

14. Fosbøl EL, Folke F, Jacobsen S, et al. Cause-specific cardiovascular risk associated with nonsteroidal antiinflammatory drugs among healthy individuals. Circ Cardiovasc Qual Outcomes. 2010;3(4): 395-405.

15. Schjerning Olsen AM, Fosbøl EL, Lindhardsen J, et al. Duration of treatment with nonsteroidal anti-inflammatory drugs and impact on risk of death and recurrent myocardial infarction in patients with prior myocardial infarction: a nationwide cohort study. Circulation. 2011;123(20):2226-2235.

16. Capone ML, Sciulli MG, Tacconelli S, et al. Pharmacodynamic interaction of naproxen with low-dose aspirin in healthy subjects. $J$ Am Coll Cardiol. 2005;45(8):1295-1301.

17. Gengo FM, Rubin L, Robson M, et al. Effects of ibuprofen on the magnitude and duration of aspirin's inhibition of platelet aggregation: clinical consequences in stroke prophylaxis. J Clin Pharmacol. 2008;48(1):117-122.

18. Cheetham TC, Levy G, Niu F, Bixler F. Gastrointestinal safety of nonsteroidal antiinflammatory drugs and selective cyclooxygenase-2 inhibitors in patients on warfarin. Ann Pharmacother. 2009;43(11): 1765-1773.

19. Whelton A. Nephrotoxicity of nonsteroidal anti-inflammatory drugs: physiologic foundations and clinical implications. Am J Med. 1999;106(5B):13S-24S.

20. Barkin RL, Buvanendran A. Focus on the COX-1 and COX-2 agents: renal events of nonsteroidal and anti-inflammatory drugs-NSAIDs. Am J Ther. 2004;11(2):124-129.

21. Richy F, Bruyere O, Ethgen O, et al. Time dependent risk of gastrointestinal complications induced by non-steroidal anti-inflammatory drug use: a consensus statement using a meta-analytic approach. Ann Rheum Dis. 2004;63(7):759-766.

22. Hippisley-Cox J, Coupland C. Risk of myocardial infarction in patients taking cyclo-oxygenase-2 inhibitors or conventional non-steroidal anti-inflammatory drugs: population based nested case-control analysis. BMJ. 2005;330(7504):1366

23. Hippisley-Cox J, Coupland C, Logan R. Risk of adverse gastrointestinal outcomes in patients taking cyclo-oxygenase- 2 inhibitors or conventional non-steroidal anti-inflammatory drugs: population based nested case-control analysis. BMJ. 2005;331(7528):1310-1316.

24. Huerta C, Castellsague J, Varas-Lorenzo C, Rodríguez LA. Nonsteroidal anti-inflammatory drugs and risk of ARF in the general population. Am J Kidney Dis. 2005;45(3):531-539.

25. Motsko SP, Rascati KL, Busti AJ, et al. Temporal relationship between use of NSAIDs, including selective COX-2 inhibitors, and cardiovascular risk. Drug Saf. 2006;29(7):621-632.

26. Antman EM, Bennett JS, Daugherty A, Furberg C, Roberts H, Taubert KA; American Heart Association. Use of nonsteroidal antiinflammatory drugs: an update for clinicians: a scientific statement from the American Heart Association. Circulation. 2007;115(12):1634-1642.
27. Boers M, Tangelder MJ, van Ingen H, Fort JG, Goldstein JL. The rate of NSAID-induced endoscopic ulcers increases linearly but not exponentially with age: a pooled analysis of 12 randomised trials. Ann Rheum Dis. 2007;66(3):417-418.

28. Franceschi M, Di Mario F, Leandro G, Maggi S. Pilotto A. Acid-related disorders in the elderly. Best Pract Res Clin Gastroenterol. 2009;23(6): 839-848.

29. Lanas A, Tornero J, Zamorano JL. Assessment of gastrointestinal and cardiovascular risk in patients with osteoarthritis who require NSAIDs: the LOGICA study. Ann Rheum Dis. 2010;69(8):1453-1458.

30. Chan FK. Primer: managing NSAID-induced ulcer complications balancing gastrointestinal and cardiovascular risks. Nat Clin Pract Gastroenterol Hepatol. 2006;3(10):563-573.

31. Zhang W, Doherty M, Leeb BF, et al. EULAR evidence based recommendations for the management of hand osteoarthritis: report of a Task Force of the EULAR Standing Committee for International Clinical Studies Including Therapeutics (ESCISIT). Ann Rheum Dis. 2007;66(3):377-388.

32. Zhang W, Moskowitz RW, Nuki G, et al. OARSI recommendations for the management of hip and knee osteoarthritis, Part II: OARSI evidence-based, expert consensus guidelines. Osteoarthritis Cartilage. 2008;16(2):137-162.

33. Kneer W, Rother I, Rother M, Seidel E; IDEA-033-III-01 Study Group. A multiple-dose, open-label, safety, compliance, and usage evaluation study of epicutaneously applied Diractin (ketoprofen in Transfersome) in joint/musculoskeletal pain or soft tissue inflammation. Curr Drug Saf. 2009;4(1):5-10.

34. Wiechers JW. The barrier function of the skin in relation to percutaneous absorption of drugs. Pharm Weekbl Sci. 1989;11(6):185-198.

35. Komatsu T, Sakurada T. Comparison of the efficacy and skin permeability of topical NSAID preparations used in Europe. Eur J Pharm Sci. 2012;47(5):890-895.

36. Barkin RL. Topical Nonsteroidal Anti-Inflammatory Drugs: The Importance of Drug, Delivery, and Therapeutic Outcome. Am J Ther. Epub February 22, 2012.

37. Sarigüllü Ozgüney I, Yeşim Karasulu H, Kantarci G, Sözer S, Güneri T, Ertan G. Transdermal delivery of diclofenac sodium through rat skin from various formulations. AAPS PharmSciTech. 2006;7(4):88.

38. Haroutiunian S, Drennan D, Lipman A. Topical NSAID therapy for musculoskeletal pain. Pain Med. 2010;11(4):535-549.

39. Banning M. Topical diclofenac: clinical effectiveness and current uses in osteoarthritis of the knee and soft tissue injuries. Expert Opin Pharmacother. 2008;9(16):2921-2929.

40. Kienzler JL, Gold M, Nollevaux F. Systemic bioavailability of topical diclofenac sodium gel 1\% versus oral diclofenac sodium in healthy volunteers. J Clin Pharmacol. 2010;50(1):50-61.

41. Brunner M, Dehghanyar P, Seigfried B, Martin W, Menke G, Müller M. Favourable dermal penetration of diclofenac after administration to the skin using a novel spray gel formulation. Br J Clin Pharmacol. 2005;60(5):573-577.

42. Massey T, Derry S, Moore RA, McQuay HJ. Topical NSAIDs for acute pain in adults. Cochrane Database Syst Rev. 2010;(6):CD007402.

43. Dray A. Inflammatory mediators of pain. Br J Anaesth. 1995;75(2): $125-131$.

44. Heyneman CA, Lawless-Liday C, Wall GC. Oral versus topical NSAIDs in rheumatic diseases: a comparison. Drugs. 2000;60(3):555-574.

45. Castelnuovo E, Cross P, Mt-Isa S, Spencer A, Underwood M; TOIB study team. Cost-effectiveness of advising the use of topical or oral ibuprofen for knee pain; the TOIB study [ISRCTN: 79353052]. Rheumatology (Oxford). 2008;47(7):1077-1081.

46. Mason L, Moore RA, Edwards JE, Derry S, McQuay HJ. Topical NSAIDs for chronic musculoskeletal pain: systematic review and meta-analysis. BMC Musculoskeletal Disord. 2004;5:28.

47. Galer BS, Rowbotham M, Perander J, Devers A, Friedman E. Topical diclofenac patch relieves minor sports injury pain: results of a multicenter controlled clinical trial. J Pain Symptom Manage. 2000;19(4): 287-294. 
48. Voltaren ${ }^{\circledR}$ Gel (diclofenac sodium topical gel) $1 \%$ [package insert]. Chadds Ford, PA: Endo Pharmaceuticals Inc.; 2009.

49. PENNSAID ${ }^{\circledR}$ (diclofenac sodium topical solution) $1.5 \% \mathrm{w} / \mathrm{w}$ [package insert]. Hazelwood, MO: Mallinckrodt Brand Pharmaceuticals, Inc; 2010.

50. Flector ${ }^{\circledR}$ Patch (diclofenac epolamine patch) 1.3\% [package insert]. Bristol, TN: King Pharmaceuticals Inc; 2011.

51. Herndon CM. Topical delivery of nonsteroidal anti-inflammatory drugs for osteoarthritis. J Pain Palliat Care Pharmacother. 2012;26(1): $18-23$.

52. Lin J, Zhang W, Jones A, Doherty M. Efficacy of topical non-steroidal anti-inflammatory drugs in the treatment of osteoarthritis: meta-analysis of randomised controlled trials. BMJ. 2004;329(7461):324.

53. Barthel HR, Haselwood D, Longley S 3rd, Gold MS, Altman RD. Randomized controlled trial of diclofenac sodium gel in knee osteoarthritis. Semin Arthritis Rheum. 2009;39(3):203-212.

54. Roth SH, Shainhouse JZ. Efficacy and safety of a topical diclofenac solution (pennsaid) in the treatment of primary osteoarthritis of the knee: a randomized, double-blind, vehicle-controlled clinical trial. Arch Intern Med. 2004;164(18):2017-2023.

55. Brühlmann P, Michel BA. Topical diclofenac patch in patients with knee osteoarthritis: a randomized, double-blind, controlled clinical trial. Clin Exp Rheumatol. 2003;21(2):193-198.

56. Simon LS, Grierson LM, Naseer Z, Bookman AA, Zev Shainhouse J. Efficacy and safety of topical diclofenac containing dimethyl sulfoxide (DMSO) compared with those of topical placebo, DMSO vehicle and oral diclofenac for knee osteoarthritis. Pain. 2009;143(3):238-245.

57. Tugwell PS, Wells GA, Shainhouse JZ. Equivalence study of a topical diclofenac solution (pennsaid) compared with oral diclofenac in symptomatic treatment of osteoarthritis of the knee: a randomized controlled trial. J Rheumatol. 2004;31(10):2002-2012.

58. Derry S, Moore RA, Rabbie R. Topical NSAIDs for chronic musculoskeletal pain in adults. Cochrane Database Syst Rev. 2012;9:CD007400.

59. Makris UE, Kohler MJ, Fraenkel L. Adverse effects of topical nonsteroidal antiinflammatory drugs in older adults with osteoarthritis: a systematic literature review. J Rheumatol. 2010;37(6):1236-1243.

60. Zacher J, Altman R, Bellamy N, et al. Topical diclofenac and its role in pain and inflammation: an evidence-based review. Curr Med Res Opin. 2008;24(4):925-950.

61. Zacher J, Burger KJ, Färber L, Gräve M, Abberger H, Bertsch K. Topical diclofenac versus oral ibuprofen: a double blind, randomized clinical trial to demonstrate efficacy and tolerability in patients with activated osteoarthritis of the finger joints (Heberden and/or Bouchard Arthritis). Akt Rheumatol. 2001;26(1):7-14. German.

62. Baraf HS, Gold MS, Petruschke RA, Wieman MS. Tolerability of topical diclofenac sodium $1 \%$ gel for osteoarthritis in seniors and patients with comorbidities. Am J Geriatr Pharmacother. 2012;10(1):47-60.
63. Peniston JH, Gold MS, Wieman MS, Alwine LK. Long-term tolerability of topical diclofenac sodium $1 \%$ gel for osteoarthritis in seniors and patients with comorbidities. Clin Intervent Aging. 2012;7:517-523.

64. Roth SH, Fuller P. Diclofenac topical solution compared with oral diclofenac: a pooled safety analysis. J Pain Res. 2011;4:159-167.

65. Altman RD, Barthel HR. Topical therapies for osteoarthritis. Drugs. 2011;71(10):1259-1279.

66. Hochberg MC, Altman RD, April KT, et al; American College of Rheumatology. American College of Rheumatology 2012 recommendations for the use of nonpharmacologic and pharmacologic therapies in osteoarthritis of the hand, hip, and knee. Arthritis Care Res. 2012;64(4): 465-474.

67. American Academy of Orthopaedic Surgeons (AAOS). Treatment of Osteoarthritis of the Knee: Evidence-Based Guideline. 2nd ed. Rosemont, IL: AAOS; 2013. Available from: http://www.aaos.org/ oakcpg/. Accessed December 9, 2013.

68. National Institute for Health and Clinical Excellence (NICE). Osteoarthritis: the care and management of osteoarthritis in adults. NICE clinical guideline 59. London: NICE; 2008. Available from: http:// www.nice.org.uk/nicemedia/pdf/cg59niceguideline.pdf. Accessed December 9, 2013.

69. Conaghan PG, Dickson J, Grant RL; Guideline Development Group. Care and management of osteoarthritis in adults: summary of NICE guidance. BMJ. 2008;336(7642):502-503.

70. Jordan KM, Arden NK, Doherty M, et al; Standing Committee for International Clinical Studies Including Therapeutic Trials ESCISIT. EULAR Recommendations 2003: an evidence based approach to the management of knee osteoarthritis: Report of a Task Force of the Standing Committee for International Clinical Studies Including Therapeutic Trials (ESCISIT). Ann Rheum Dis. 2003;62(12):1145-1155.

71. American Academy of Orthopaedic Surgeons. Treatment of Osteoarthritis of the Knee (Non-Arthroplasty). Rosemont, IL: American Academy of Orthopaedic Surgeons, 2008.

72. American Geriatrics Society Panel on Pharmacological Management of Persistent Pain in Older Persons. Pharmacological management of persistent pain in older persons. J Am Geriatr Soc. 2009;57(8):1331-1346.

73. American Pain Society. Guideline for the Management of Pain in Osteoarthritis, Rheumatoid Arthritis, and Juvenile Chronic Arthritis. 2nd ed. Glenview, IL: American Pain Society; 2002.

74. Manchikanti L, Boswell MV, Giordano J. Evidence-based interventional pain management: principles, problems, potential and applications. Pain Physician. 2007;10(2):329-356.
Journal of Pain Research

\section{Publish your work in this journal}

The Journal of Pain Research is an international, peer-reviewed, open access, online journal that welcomes laboratory and clinical findings in the fields of pain research and the prevention and management of pain. Original research, reviews, symposium reports, hypothesis formation and commentaries are all considered for publication.

\section{Dovepress}

The manuscript management system is completely online and includes a very quick and fair peer-review system, which is all easy to use. Visit http://www.dovepress.com/testimonials.php to read real quotes from published authors. 